\title{
Comparison of Lipid Profile in Obese-Hypertensive and Non Hypertensive
}

\author{
Mutiara Indah Sari ${ }^{1}$ \\ Departement of Biochemistry, Faculty of Medicine \\ Universitas Sumatera Utara \\ Medan, Indonesia \\ muti_dr@yahoo.com \\ Rusdiana $^{2}$ \\ Departement of Biochemistry , Faculty of Medicine \\ Universitas Sumatera Utara \\ Medan, Indonesia
}

\author{
Siti Syarifah ${ }^{3}$ \\ Departement of Pharmacology and Therapeutic, Faculty of \\ Medicine \\ Universitas Sumatera Utara \\ Medan, Indonesia \\ Dewi Indah Sari ${ }^{4}$ \\ Departement of Clinical Pathology, Faculty of Medicine \\ Universitas Sumatera Utara \\ Medan, Indonesia
}

\author{
Maya Savira ${ }^{5}$ \\ Departement of Physiology, Faculty of Medicine \\ Universitas Sumatera Utara \\ Medan, Indonesia
}

\begin{abstract}
Obesity is one of the world's health problems. The increase in obesity is associated with increasing degenerative diseases such as hypertension. Hypertension is one of the main risk factors for mortality in the world. One of comorbid disease in patients with hypertension will increase mortility is dyslipidemia or disorder of lipid profiles. The aim of this study to determine the comparison in lipid profiles between obesehypertensive and non hypertensive. A cross-sectional study was carried out among forty obese participants. Blood pressure measurement using a mercury sphygmomanometer. Hypertension was defined as systolic blood pressure (SBP) up to $140 \mathrm{mmHg}$ and/or diastolic blood pressure (DBP) up to 90 mmHg. Serum lipid profiles such as total cholesterol (TC), lowdensity lipoprotein (LDL), triglycerides (TG) and high density lipoprotein (HDL were measured using the cobas 6000, series 501 after subjects had fasted for $\mathbf{1 2}$ hours. The results shows that seventeen of obese participants were hypertensive and twenty three were non hypertensive. The TC, LDL and TG levels increases in obese hypertensive more than in non-hypertensive while HDL decreases in hypertensive patients. The TC and TG level $(\mathrm{mg} / \mathrm{dl})$ in obese hypertensive compared in obese non hypertensive were 203.64 vs 183.25 ; 168.70 vs 112.91 which the independent-samples $t$ test showed significant different. The present findings show that serum total cholesterol and triglyceride levels are significant changes in obese hypertensive patients than in obese non hypertensive.
\end{abstract}

Keywords-Lipid profiles; blood presusure, obese hypertensive, obese non hypertensive

\section{INTRODUCTION}

Obesity is one of the world's health problems are increasingly common, associated with the development of some of the most prevalent diseases of modern society. Obesity increases risks of cardiovascular diseases such as hypertension. Obesity is closely related to an increased risk of hypertension. Acumulation of fat in body can cause blockage in the blood vessels so that the heart works hard in pumping blood that causes increased blood pressure/ hypertension. [1].

According to The Third National Health and Nutrition Survey (NHANES III), the risk of hypertension has significantly increased in men and women with obesity [2]. The World Health Organization (WHO) reports, that in 2012 at least 839 million cases of hypertension and is estimated in $2025,29 \%$ of the total world population, risky become obesity [3]. Of 839 million people with hypertension, 333 million are in developed countries while the remaining 639 million are in developing countries. In Indonesia, in 2007, the prevalence of hypertension in urban and rural areas range from $17-21 \%$, but the data nationally is not yet complete. Most people with hypertension in Indonesia are undetectable, while those detected are unaware of the condition of the disease. Hypertension is the third leading cause of death reaching 6.8\% of the population mortality at all ages in Indonesia [4].

Hypertension is a chronic disease that where the increase of blood pressure happened within a period long). Patients who have at least three reads of blood pressure which is exceeding $140 / 90 \mathrm{mmHg}$ when taking a rest. It is estimated has the status of blood pressure

One of comorbid disease in patients with hypertension will increase mortality is dyslipidemia [5]. Hpertension and dyslipidemia often coincide happens. Each is risk factor for cardiovascular disease. Dyslipidemia can be defined as a lipid metabolic disorder which there is an increase or decrease in the lipid component in the blood. Blood lipids that used as a measurement of dyslipidaemia are types of triglycerides, total cholesterol, high-density lipoprotein (HDL) and low density lipoprotein (LDL). TC, TG, HDL and LDL call as lipid profiles. Several previous studies showed the relationship between dyslipidemia and hypertension [6], [7]. Hypertension is associated with dyslipidemia in many ways and contributes. Hypertension and dyslipidemia are related with oxidative 
stress and are major causes of cardiovascular disease. It is widely accepted that cardiovascular disease is associated with hypertension. The increasing of the TC, LDL, and TG and decreasing of HDL are risk factor for mortality from cardiovascular disease [8].

The aim of this study was to determine the comparisonin lipid profiles between obese-hypertensive and non hypertensive.

\section{METHODS}

This study is conducted after getting permission from ethical committee. This study was conducted after getting permission from ethical committee of Faculty of Medicine of University of Sumatera Utara No. 595/ KEPK FK USU-RSUP HAM/2016. Subject that agree to participate the study were asked to fill out and sign an informed consent after being given an explanation about the purpose and benefits of the research.

\section{A. Type of study}

This study was a cross sectional study, conducted at Teguh Murni, Hospital, Medan.

\section{B. Measured of Body Mass Index to Determine of Obesity}

Body mass index (BMI) is an anthropometric measure that describes nutritional status. To determine the BMI is done by measurement of body weight and height Body weight and height is measured by using digital scale with maximum capacity $150 \mathrm{~kg}$, microtoise maximum length $200 \mathrm{~cm}$. BMI is calculated by dividing weight and square of height. BMI $>25$ $\mathrm{kg} / \mathrm{m}^{2}$ was classify as obesity. [8].

\section{Measured of Blood Pressure to Deternine of Hypertension}

Hypertension participants were selected and diagnosed based on their history, physical examination according to the JNC 7 (Joint National Committee on Prevention, Detection, Evaluation, and Treatment of High Blood Pressure Criteria) for the diagnosis of hypertension[9]. Physical examination for hypertension was measured of blood pressure (BP) while participants were sitting after at least 10 min of rest.

The measurement was on the cubital fossa supported at heart level of participants and using a mercury sphygmomanometer which had been calibrated before. The systolic blood pressure (SBP) was defined by the onset of the first Korotkoff sound, and diastolic blood pressure (DBP) was indicated by disappearance of Korotkoff sound. Two measurements of blood pressure were taken and hypertension was defined as SBP $\geq 140 \mathrm{mmHg}$ and/or DBP $\geq 90 \mathrm{mmHg}$. Blood pressure measurement was performed twice. If the first and second blood pressure difference measurements are greater than $10 \mathrm{mmHg}$ then the blood pressure measurement is performed again after the rest for 2-3 minutes. Differences of $<5 \mathrm{mmHg}$ were allowed.

\section{Measured of Blood}

Lipid profile was measured using a cobas 6000 series 501 (enzyme method) from blood sample participant after at least twelve-hour fasting.

\section{E. Analysis of observations}

In this research, the results of data analysis done by univariate and bivariate analysis. Univariable analysis is a descriptive analysis to describe the characteristics of each variable (age, sex, weight, height, blood pressure, lipid profiles) with frequency distribution that will be presented in the form of narration and tabulation. The normality test with Kolmogorov Smirnov test was performed to determine the bivariate correlation test to be used. The quantitative data was expressed as mean \pm SD. Spearman's correlation test was used to see the correlation of blood pressure with BMI The independent t-test were used to see the relationship lipid profiles with blood pressure with SPSS version 16 sotfware.

\section{RESULTS AND DISCUSSION}

This study was done on forty subjects who were willing to participant as subject research respondents. Characteristics of variable of this study can be seen in table 1 .

TABLE 1. CHARACTERISTICS OF STUDY POPULATION

\begin{tabular}{|l|l|l|}
\hline \multicolumn{1}{|c|}{ Variables } & \multicolumn{1}{c|}{ N,Mean, SD } & \multicolumn{1}{c|}{ Min, Max } \\
\hline Age (year) & $39.10 \pm 11.65$ & $20.00 ; 67.00$ \\
\hline Sex: Male n(\%) & $24(60.00)$ & \\
\hline \multicolumn{1}{|c|}{ Female n(\%) } & $16(40.00)$ & \\
\hline Anthropometry & & \\
\hline Height $(\mathrm{cm})$ & $163.25 \pm 8.95$ & $148.50 ; 180.00$ \\
\hline BodyWeight $(\mathrm{kg})$ & $87.82 \pm 17.76$ & $60.00 ; 129.30$ \\
\hline BMI $\left(\mathrm{kg} / \mathrm{m}^{2}\right)$ & $32.65 \pm 4.73$ & $25.60 ; 45.31$ \\
\hline SBP $(\mathrm{mmHg})$ & $130.90 \pm 17.88$ & $103.00 ; 179.00$ \\
\hline DBP $(\mathrm{mmhg})$ & $83.87 \pm 9.03$ & $66.00 ; 104.00$ \\
\hline Hypertensive $(\%)$ & $17(42.50)$ & \\
\hline Non-Hypertensive $(\%)$ & $23(57.50)$ & \\
\hline TC & $191.92 \pm 31.21$ & $119.00 \pm 269.00$ \\
\hline HDL & $53.02 \pm 12.64$ & $34.00 ; 86.00$ \\
\hline LDL & $126.30 \pm 24.98$ & $47.00 ; 174.00$ \\
\hline TG & $136.62 \pm 79.47$ & $46.00 ; 452.00$ \\
\hline
\end{tabular}

Correlation of blood pressure with BMI in study population is shown at table 2 . 
TABLE 2. CORRELATIONS BETWEEN BMI WITH SBP AND DBP

\begin{tabular}{|c|c|c|}
\hline Variable & \multicolumn{2}{|c|}{ BMI } \\
\hline & $\mathbf{p}^{*}$ & $\mathbf{r}$ \\
\hline DBP & 0.039 & 0.327 \\
\hline SBP & 0.048 & 0.315 \\
\hline
\end{tabular}

Lipid profiles of the hypertensive and non-hypertensive obese participants is shown at table 3 .

TABLE 3.L IPID PROFILE AND HYPERTENSIVE AND NONHYPERTENSIVE OBESE SUBJECTS

\begin{tabular}{|c|c|c|c|}
\hline \multirow{2}{*}{$\begin{array}{c}\text { Lipid Profiles } \\
\text { (mg/dl) }\end{array}$} & \multicolumn{2}{|c|}{ Blood Pressure } & \multirow[t]{2}{*}{$\mathbf{p}^{*}$} \\
\hline & Hypertensive & Non-Hypertensive & \\
\hline $\mathrm{TC}$ & $203.64 \pm 17.32$ & $183.24 \pm 36.39$ & 0.039 \\
\hline LDL & $133.47 \pm 13.39$ & $121.00 \pm 29.93$ & 0.12 \\
\hline HDL & $51.74 \pm 12.26$ & $53.94 \pm 13.10$ & 0.59 \\
\hline TG & $168.70 \pm 27.83$ & $112.91 \pm 17.02$ & 0.026 \\
\hline
\end{tabular}

$\mathrm{p}^{*}=$ the independent-samples $\mathrm{t}$ test

In this research, table 1 shown, twenty-four of forty participants who obesity were male and sixteen of forty participants were female. The characteristic mean of age was $39.10 \pm 11.65$ years old. The mean BMI of participants was $32.45 \mathrm{~kg} / \mathrm{m}^{2}$. At Indonesian, the BMI value that normal category was $23-25 \mathrm{~kg} / \mathrm{m}^{2}$. There is an increasing prevalence of obesity, especially in developing countries. The prevalence of obesity in developing countries relationship with calorie intake and physical activity [10]. In developing countries, people tends to consume high-calorie fast food. Lifestyle changes such as a diet that leads to ready-to-eat foods that contain lots of fat, protein and high salt and low fiber is one of the factors causing obesity [11].

Obesity is not just about the number of eating foods but also the lack of physical activity. The development of technology leads to various lifestyle changes, especially in physical activity. Technological development in developing countries cause many activities can be done easily and quickly. So, that is make people had low physical activity. For examples, the use of computer will cause a person to play game on line instead of playing soccer in the soccer field, and many other examples [12]. Low physical activity was contributed increasing prevalence obesity.

Obesity is one of risk factor that cause degenerative disease such as diabetes mellitus, coronary heart disease and hypertension. In this research found that the mean of systolic blood pressure $(\mathrm{mmHg})$ and diastolic blood pressure $(\mathrm{mmHg})$ of the obesity participants were $130.90 \pm 17.88 ; 83.87 \pm 9.03$ and seventeen of obese participants were hypertensive and twenty three were non hypertensive.

Table 2 shows that BMI and SBP was significantly correlated (spearman's correlation $\mathrm{p}=0.039, \mathrm{r}=0.327$ ). The correlation was also seen in the relationship between BMI and SBP with spearman's correlation test $p=0.048(r=0.315)$. Previous Studies in Shiraz hospital showed that BMI had direct relationship with systolic and diastolic blood pressure [13]. The present research is consistent with the research at Minangkabau ethnic communities in Padang city [14].

People who are obese, their body will work hard to burn off excess calories intake. Burning calories requires supply enough oxygen in the blood. The more calories burn, the more the supply of oxygen in the blood. The amount of blood supply certainly makes the heart work harder. The impact of bloodpressure of obese people tend to be high, so that hypertension can occur [15].

Table 3 shown that mean of TC, LDL and TG levels increases in obese hypertensive more than in obese nonhypertensive subjects while HDL decreases in obese hypertensive participants. The mean and SD of TC, TG, and LDL in obese hypertensive patients were higher than non hypertensive individuals ( $203.64 \pm 17.32$ vs $183.25 \pm 36.39$; $168.70 \pm 92.70$ vs $112.91 \pm 59 ; 133.47 \pm 13.39$ vs $121.00 \pm 29.93$ ) meanwhile the mean and SD of HDL in obese hypertensive patients were lower than non hypertensive individuals (51.74 \pm 12.26 vs $53.94 \pm 13.10)$.

The research by Sarwar (2017) shown the similar findings with the present study. There were observed serum TC, LDL and TG concentrations and found significantly higher in hypertensive patients whereas the level of HDL cholesterol was significantly lower in hypertensive patients [16].

The higher level of serum TC, LDL and TG may be due to genetic factors and increased consumption of dietary animal fat, lack of physical exercise or metabolic disorders e.g. diabetes and hypothyroidism. Increased serum TC, TG, LDL levels and decreased HDL termed as dyslipdemia 17].

Dyslipidemia comprising altered ratio of high to TC level and isolated evaluation of the LDL or TG is usually associated with hypertension. Dyslipidemia is one of comorbid disease in patients with hypertension will increase mortility.

The independent $\mathrm{t}$-test showed that were significant different of TC and TG in obese hypertensive patients compared non hypertensive. ( $p=0.039$ and $p=0.026$ ). Few studies showed the significance of association between hypertension and TC, HDL, LDL and TG [18], [19], [20]. Another study, similar with this present study which was carried outat the Minangkabau ethnic communities in 8 district in Padang city showed there was relation between TC as well as TG and hypertension.

Hypertension and dyslipidemia are major risk factors for cardiovascular diseases [21]. About $80 \%$ of hypertensive persons have co morbidities such as obesity, low HDL, high LDL and increased triglycerides. Hypertension and dyslipidaemia are well known to frequently coexist. The coexistence of hypertension and dyslipidaemiah as multidimensional clinical implications. CVD risk is synergistically enhanced and for this reason, both conditions should be treated aggressively. This association has been linked to obesity [22].

TC is including the family of lipid profiles. The presence of TC in body has a function as nutrients which are badly needed by the body. beside the other nutrients such as carbohydrates, proteins, vitamins, and mineral. Increasing of 
TC are very easily sticking in the vessel wall coronary blood, so it raises plaque that assciation with the onset of hypertension.

In general, the high blood pressure will show the increasing of TG levels. In hypertension, the high level of TG, and lack of fiber, lack of exercise are at risk of atherosclerosis. For a long time the TG excess, it will accumulate in the blood vessel walls, this deposit is called atheromatous plaques. This plaque will grow larger, and will reduce the diameter of the blood vessels so that it becomes narrow. Eventually there will be a blockage of blood flow, so it takes great pressure to drain the blood throughout the body. When the muscle cells of the arteries buried in the fat. Then the elasticity will disappear and cannot control the blood pressure, the result is the hypertension happened.

In this research, there were no significant difference LDL and HDL levels between hypertensives patient and nonhypertensive-obese subjects $(\mathrm{p}=0.12$ and $\mathrm{p}=0.59)$.

The results similarly previous study Feryadi, (2014) shows HDL and LDL had not significant relation with hypertension

LDL as a carrier of cholesterol in the blood, when excessive levels will settle on the walls of arteries and form plaque and cause constriction and even closure of blood vessels (atherosclerosis) [23].

HDL is a lipid compound containing $52 \%$ protein and $48 \%$ fat. HDL is formed in the liver cells and small intestinal cells. The main function of HDL was transporting cholesterol and phospholipids from tissue or peripheral cells to the liver for reorganization prevents the buildup of cholesterol in peripheral cells. Decreased HDL levels will lead to increased levels of cholesterol in the tissues and blood circulation. A decrease in HDL levels up to $<35 \mathrm{mg} / \mathrm{dl}$ is a potential risk factor for hypertension [24].

In this study, although the mean LDL and HDL obese hypertensive levels were higher than non obese-hypertensive (LDL level of obese hypertensive was $133.47 \mathrm{mg} / \mathrm{dl}$, LDL level of obese non hypertensive was $121.00 \mathrm{mg} / \mathrm{dl}$ and HLD level of of obese hypertensive was $51.74 \mathrm{mg} / \mathrm{dl}$, LDL level of obese non hypertensive was $53.94 \mathrm{mg} / \mathrm{dl}$ ) obese but the values of LDL and HDL from within the normal category. This may be the cause so there is no relationship between LDL and HDL levels with hypertension.

\section{IV.CONCLUSION}

In this study showed that TC, LDL and TG levels increases in obese hypertensive patients more than in non-hypertensive subjects while HDL decreases in in hypertensive patients. There were significant different of TC and TG in obese hypertensive patients compared non hypertensive. While there were no significant difference LDL and HDL levels between hypertensives patient and non-hypertensive-obese subjects. The present findings show that serum total cholesterol and triglyceride levels are significant changes in obese hypertensive patients than in obese non hypertensive. This study indicate that lipid profiles has association with hypertension.

\section{ACKNOWLEDGMENT}

The writer gratefully acknowledge that this research is supported by Institutions of Research as Talenta Research USU of Year 2016 Universitas Sumatera Utara (USU), and support by Faculty Medicine of USU

\section{REFERENCES}

[1] R.W. O'Rourke, "Inflammation in obesity-related disease Surgery," vol.145 (3), 2009, pp. 255-259. DOI: 10.1016/j.surg.2008.08.038.

[2] I. Vane`čkova', L. Maletı́nska', M. Behuliak, V Nagelova', J Zicha and J Kunes, "Obesity-related hypertension: possible pathophysiological Mechanisms. Journal of Endocrinology 223, 2009, R63-R78. DOI:10.1530/JOE-14-0368.

[3] World Health Organization, "Non communicable disease: hypertension. geneva:regional office for South-East Asia. Department of Sustainable Development and Healthy Environments, 2011.

[4] Ministry of Health, " The Health Profile of Indonesia Year 2008," Jakarta, 2008.

[5] A. Alkerwiet, S. Pahny, M. Lair, C. Delagardelle, J Beissel, "Level of unawareness and management of diabetes, hypertension, and dyslipidemia among adults in luxembourg: findings from ORISCAVLUX Study," PIOS one, vol.8:3, 2013, Doi:10.1371/journal.pone.0057920.

[6] A. Srivastava, B. K. Binawara, "Comparative Study on lipid profile of hypertensive patients and non-hypertensive individuals in bikaner, rajasthan, india," UK Journal of Pharmaceutical and Bioscience vol. 4(4), 2016, pp. 62-66, http://dx.doi.org/10.20510/ukjpb/4/i4/112412.

[7] C.U. Osuji, E.G. Omejua, E. I. Onwubuya and G. I. Ahaneku, " Serum lipid profile of newly diagnosed hypertensive patients in nnewi, southeast nigeria. Int J Hypertens, 2012, 710486. doi: 10.1155/2012/710486.

[8] A.S. Fauci, E. Braunwald and D.L Kasper, "Harrison's.principlesof internal medicine. Ed $17^{\text {th }}$, 2008, pp. 2042-2059. New York: McGraw- Hill Companies, Inc

[9] A. V. Chobanian, G. L. Bakris, and H. R. Black, "The seventh report of the Joint National Committee on Prevention, Detection, Evaluation, and Treatment of High Blood Pressure: the JNC 7 report," Journal of the AmericanMedical Association, vol. 289(19), 2003, pp. 2560-2572.

[10] M.I. Sari and D.I. Sari, "Nutrient intake, apolipoprotein A5 -1131T>C polymorphism and its relationship with Obesity," Materials Science and Engineering 180, 2017, 012094 doi:10.1088/1757899X/180/1/0120941011001

[11] M.I. Sari and D.W. Wijaya, "Relationship between calorie intake, physical activity, and dopamine D2 receptor Taq1A gene polymorphism in normal-weight, overweight, and obese students of the faculty of medicine of university of Sumatera Utara," Bali Medical Journal, vol. 6(1), 2017, pp. 114-118. DOI:10.15562/bmj.v6i1.394

[12] F. Booth, C. Roberts, \& M.Laye ," Lack of Exercise is a Major Cause of Chronic Disease,". Compr Physiol. 2012.2(2):1143-211

[13] R. Sahebi and L. Sahebi, "Prevalence and determinants of overweight and obesity in the workers of Shiraz hospitals," Bangladesh Journal of Medical Science, vol.13:03, 2014, DOI: http://dx.doi.org/10.3329/bjms.v13i3.10897.

[14] D. Sulastri, Elmatris and R. Ramadhani, "Obesity relationship with hypertension occurrence minangkabau ethnic community in padang," Transl. MajalahKedokteranAndalas, vol. 2(36), 2012.

[15] M.I. Wahba and R.H. Wahba, "Obesity and obesity. inisiated metabolic syndrome: mechanistic link to chronic kidney disease," Clin J Am SocNephrol, 2007, pp. 2:550-562. doi: 10.2215/CJN.04071206.

[16] M.S. Sarwar, "Evaluation of serum lipid profile in patients with hypertension living in a coastal region of Bangladesh," Drug Res (Stuttg), vol. 64(7), 2014, pp. 353-7. doi: 10.1055/s-0033-1358704.

[17] T. Jaaskelainen, J. Paananen, J. Lindstrom, J.G. Eriksson ,’Genetic predisposition to obesity and lifestyle factors - the combined analyses of twenty-six known BMI-and fourteen known waist:hip ratio (WHR)- 
associated variants in the Finnish Diabetes Prevention Study, Br. J. Nutr., 2013 , 110(10),

$1856-1865$

https://doi.org/10.1017/S0007114513001116

[18] Pyadala, "Assessment of lipid profile among hypertensive patients attending to a rural teaching hospital," Sangareddy.Int J Med Sci Public Health, vol. 6(1), 2017, pp. 71-74. oi: 10.5455/ijmsph.2017.20062016559.

[19] T. Saxena and S. Naz, "Assessment of HDL associated- pon-1 and lipid profile in prehypertensive and hypertensive women," Biomedical \& Pharmacology Journal, vol.8(2), 2015, pp. 591-595 DOI: http://dx.doi.org/10.13005/bpj/802.

[20] G. Ghooshchi, "Evaluation of the lipid profile of hypertensive patients compared to non- hypertensive individuals. Patient Saf Qual Improv," vol.2(3), 2014, pp. 120-122. DOI: 10.22038/psj.2014.2989

[21] J. Poss, F. Custodis, C. Werner, O. Weigartner, M. Bohm, and U. Laufs , "Cardiovascular Disease and Dyslipidemia: beyond LDL, Curr Pharm Des, 2011. 17(9), 861-80
[22] R.O. Halperin, H. D. Sesso, J. Ma, J. E. Buring, M. J. Stampfer, and J. M. Gaziano, "Dyslipidemia and the risk of incident hypertension in men," Hypertension, vol.47(1), 2006, pp. 45-50. DOI: 10.1161/01.HYP.0000196306.42418.0e.

[23] R. Feryadi, D. Sulastri, and H. Kadri, "Lipid profile levels relationship with hypertension in ethnic communities in padang minangkabau year 2012," Transl. Jurnal Kesehatan Andalas, vol. 3(2), 2014.

[24] D. McGrowder, C. Riley, E.Morrison, and I. Gordon, " The Role of High-Density Lipoproteins in Reducing the Risk of Vascular Diseases, Neurogenetive Disorders, and Cancer, Cholesterol," 2011 (011), Article ID 496925, 9 pages, http://dx.doi.org/10.1155/2011/496925 